Research Article

\title{
Morphological, Structural, and Optical Bandgap Characterization of Extracted ZnO Nanoparticles from Commercial Paste
}

\author{
Mahmoud Nabil, ${ }^{1}$ I. V. Perez-Quintana $\left(\mathbb{D},{ }^{1}\right.$ M. Acosta, ${ }^{1}$ J. A. Mendez-Gamboa, \\ and R. Castro-Rodriguez ${ }^{2}$ \\ ${ }^{1}$ Engineering School, Autonomous University of Yucatan, Merida A.P. 150/97203, Mexico \\ ${ }^{2}$ Applied Physics Department, CINVESTAV-IPN, Merida A.P. 73/97205, Mexico \\ Correspondence should be addressed to I. V. Perez-Quintana; ignacio.perez@correo.uady.mx
}

Received 8 March 2021; Revised 31 August 2021; Accepted 16 September 2021; Published 1 October 2021

Academic Editor: Hom Kandel

Copyright (c) 2021 Mahmoud Nabil et al. This is an open access article distributed under the Creative Commons Attribution License, which permits unrestricted use, distribution, and reproduction in any medium, provided the original work is properly cited.

\begin{abstract}
$\mathrm{ZnO}$ nanoparticles (NPs) were extracted from a commercial paste in both colloidal and precipitate forms. The Zetasizer analysis performed on the colloid showed $\mathrm{ZnO}$ NPs ranging from $\sim 30 \mathrm{~nm}$ to $\sim 100 \mathrm{~nm}$. Thin films of $\mathrm{ZnO}$ were deposited on glass substrates by spin-coating technique from a mixture of the extracted colloid and precipitate. The scanning electron microscope (SEM) images showed uniformly arranged, mesoporous, and nanostructured $\mathrm{ZnO}$ particles of different shapes, with an estimated film thickness of $0.67 \mu \mathrm{m}$. Analysis by energy dispersive X-ray spectroscopy (EDS) and X-ray diffraction analysis (XRD) confirmed the presence of $\mathrm{ZnO}$ in the films, with no impurities or remnants of other materials. The XRD analysis showed a polycrystalline nature of the films and identified a pure phase formation of the hexagonal wurtzite structure. The average crystallite size calculated from the diffraction peaks is $\sim 43.25 \mathrm{~nm}$. The calculated crystal tensile strain is $1.954 \times 10^{-3}$, which increases the crystal volume by $0.728 \%$ compared with the crystal volume of standard ZnO. The calculated crystal parameters are $a=b=3.258 \AA$ and $c=5.217 \AA$. The calculated dislocation density $(d)$ and bond length $\mathrm{Zn}-\mathrm{O}(L)$ are $5.35 \times 10^{-4} \mathrm{~nm}^{-2}$ and $2.695 \AA$, respectively. Ultraviolet-visible absorption spectra showed an optical band gap of $\sim 3.80 \mathrm{eV}$.
\end{abstract}

\section{Introduction}

Zinc oxide $(\mathrm{ZnO})$ is a compound of group II-VI. It is a broadband semiconductor oxide with a direct bandgap of approximately $3.37 \mathrm{eV}$ at room temperature [1]. $\mathrm{ZnO}$ has a high chemical and mechanical stability. In addition, it is nontoxic and abundantly available in nature. $\mathrm{ZnO}$ became a material of interest for different technological applications due to its high optical transmission in the visible light range. Such applications include optical devices, optoelectronics, flat screens, liquid crystal displays, transparent electronics, and thin-film photovoltaic devices [2-4]. With the advance of nanotechnology, considerable research efforts have studied the properties of $\mathrm{ZnO}$ in its nano-dimensional scale, most commonly as thin films. ZnO films attract a lot of interest for their applications in optoelectronics and photovoltaics. One of its applications is acting as an electron transport layer (ETL) in third-generation solar cells due to its high electron mobility [5]. Thin layers of nanostructured $\mathrm{ZnO}$ can function as ETL in solar cells that include organic [6], dye sensitized [7], and perovskite solar cells [8], respectively. In addition, when obtained as a mesoporous structure, it could have a possible industrial application for conjugated materials $[9,10]$. Several deposition techniques are used to grow $\mathrm{ZnO}$ films, such as thermal evaporation [11], spray pyrolysis [12], sputtering [13], laser ablation [14], and sol-gel [15] among others. In this work, we extracted the $\mathrm{ZnO}$ nanoparticles (NPs) from a commercial paste, in a colloidal form similar to that obtained through the conventional sol-gel chemical process. We obtained $\mathrm{ZnO}$ thin films by depositing the extracted $\mathrm{ZnO}$ NPs on corning glass substrates by spin-coating. Then, we used different 
characterization methods to assess their possible applications in third-generation solar cells. This work opens the door to the recycling and reuse of nanostructured oxides after recovering them from their original products. The recovered oxides can be used in different applications, such as the fabrication of solar cells to produce clean, cheap, and abundant energy.

\section{Materials and Methods}

3.36 grams of potassium hydroxide $(\mathrm{KOH})$ were dissolved in $200 \mathrm{ml}$ of water, while 30 grams of the commercial $\mathrm{ZnO}$ paste (bacitracin zinc 500 [USP'U] in $1 \mathrm{~g}$, polymyxin B sulfate 10000 [USP'U] in $1 \mathrm{~g}$, neomycin sulfate $3.5 \mathrm{mg}$ in $1 \mathrm{~g}$, pramoxine hydrochloride $10 \mathrm{mg}$ in $1 \mathrm{~g}$, Genomma lab USA Inc) in a laboratory beaker were placed on a magnetic stirring hot plate, applying a low temperature. When the paste melted, the temperature rose to $60^{\circ} \mathrm{C}$, and the $\mathrm{KOH}$ solution was dripped slowly using a Pasteur pipette. Magnetic stirring was applied during the $\mathrm{KOH}$ dripping, staring at $200 \mathrm{rpm}$, which increased with increasing the volume of the mixture in the beaker until it reached almost $400 \mathrm{rpm}$. After completing the dripping of the $\mathrm{KOH}$ solution, the sample remained under magnetic stirring of $400 \mathrm{rpm}$ at $60^{\circ} \mathrm{C}$ for 30 minutes and then removed from the magnetic stirring hot plate and placed in a stable place to cool down. During the cooling process, three layers appeared in the beaker as shown in Figure 1: a top layer of the organic materials found in the commercial paste, a layer of $\mathrm{ZnO}$ precipitate (PPT) at the bottom, and a colloid of $\mathrm{KOH}$ solution along with $\mathrm{ZnO}$ NPs in the middle. After twenty-four hours from the previous process, the top layer was separated from the beaker, and a sample was taken from the colloid layer using a pipette. Then, a magnetic stirring of $400 \mathrm{rpm}$ was applied to the colloid and the precipitate in the beaker for 18 hours. After the stirring period, the beaker was left 24 hours to stabilize, and a second sample of the colloid was taken. The two colloid samples were then characterized by the Zetasizer analysis.

Thin films of $\mathrm{ZnO}$ were deposited on clean glass substrates of $1 \mathrm{~cm}^{2}$ using a mixture from the colloid and the precipitate. The mixture was stirred for $30 \mathrm{~min}$ at $400 \mathrm{rpm}$ before the deposition to form a homogeneous suspension. The uniformity of the deposited thin films was improved after various experimental trials, changing the spin-coating parameters without changing the preparation method of the mixture. The films were deposited by a series of successive layers, using dynamic spin-coating with a rotation speed of $3000 \mathrm{rpm}$, rotation time of 15 seconds, and 5 minutes of preheating between layers at $120^{\circ} \mathrm{C}$. After the deposition of all stacked layers, the films were annealed at $550^{\circ} \mathrm{C}$ for 60 minutes. In this work, we report the results of $\mathrm{ZnO}$ thin film deposited in 5 stacked layers. The film was characterized by $\mathrm{X}$-ray diffraction (XRD), scanning electron microscopy (SEM), energy dispersive spectroscopy (EDS), and optical absorption spectra measurements.

Malvern Zetasizer Nano ZS DL was used to determine the size distribution of ZnO NPs in the colloidal solution. A JEOL JSM7600-F SEM at $15 \mathrm{kV}$ was used to examine the surface morphology of the film. The percentage of constituent

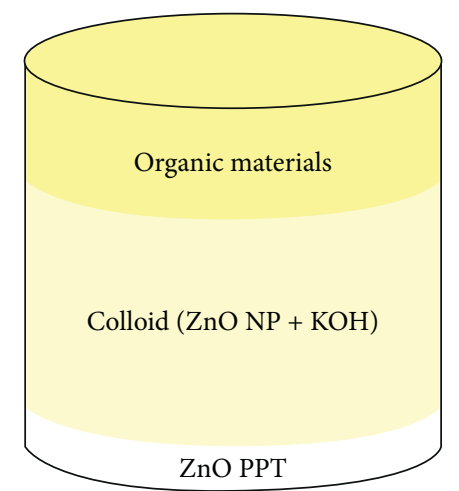

FIgURE 1: Schematic representation of the three layers after $\mathrm{ZnO}$ NP separation process.

elements was evaluated by EDS. The structural properties were determined by XRD in the grazing incidence geometry, with an inclination of $1^{\circ}$, and recorded in $2 \theta=0.02^{\circ}$ steps. The XRD beam under $\mathrm{CuK} \alpha$ filtered monochromatic radiation $(l=0.15418 \mathrm{~nm})$ at $40 \mathrm{kV}$ with $35 \mathrm{~mA}$ and an aperture diaphragm of $0.2 \mathrm{~mm}$, using a D5000 Siemens X-ray diffractometer. Based on the data obtained from the XRD analysis, we calculated the crystallographic properties of the film and compared them with the standard $\mathrm{ZnO}$ values. Optical transmittance measurements in the range of $350-1100 \mathrm{~nm}$ were performed by using a Jobin-Yvon/Spex H20-Vis spectrometer with a $0.1 \mathrm{~nm}$ resolution. Based on the data obtained from the optical measurement, we calculated the bandgap of the thin film, considering only direct transitions.

\section{Results and Discussion}

3.1. Zetasizer. The Zetasizer analysis was used to determine the size range of the NPs extracted from the paste. Figure 2(a) shows the result of the analysis performed on the first colloid sample, taken before the magnetic stirring. Two curves are observed: the first shows NP sizes ranging from $45 \mathrm{~nm}$ to $190 \mathrm{~nm}$, which represents $92.4 \%$ of the amount of $\mathrm{ZnO}$ NPs, and the second shows NP sizes ranging from $190 \mathrm{~nm}$ to $825 \mathrm{~nm}$, which represents $7.6 \%$ of the amount of $\mathrm{ZnO}$ NPs in the colloid. Figure 2(b) shows the result of the Zetasizer analysis performed on the second sample, taken after applying a magnetic stirring of $400 \mathrm{rpm}$ for 18 hours. There is a significant decrease in the volume of the second curve (particle sizes from $190 \mathrm{~nm}$ to $825 \mathrm{~nm}$ ), while the first curve became sharper (particle sizes from $35 \mathrm{~nm}$ to $100 \mathrm{~nm}$ ), representing $97.5 \%$ of the amount of $\mathrm{ZnO}$ NPs in the colloid. These results demonstrate that the developed extraction process successfully extracted the $\mathrm{ZnO}$ NPs from the commercial paste, while the subsequent magnetic stirring homogenized the extracted particles and reduced their dimensions.

3.2. SEM. SEM images were used to study the surface morphology of the deposited $\mathrm{ZnO}$ films. Figures 3(a) and 3(b) show SEM micrographs of the $\mathrm{ZnO}$ film at different spots and magnifications. The images show a mesoporous 


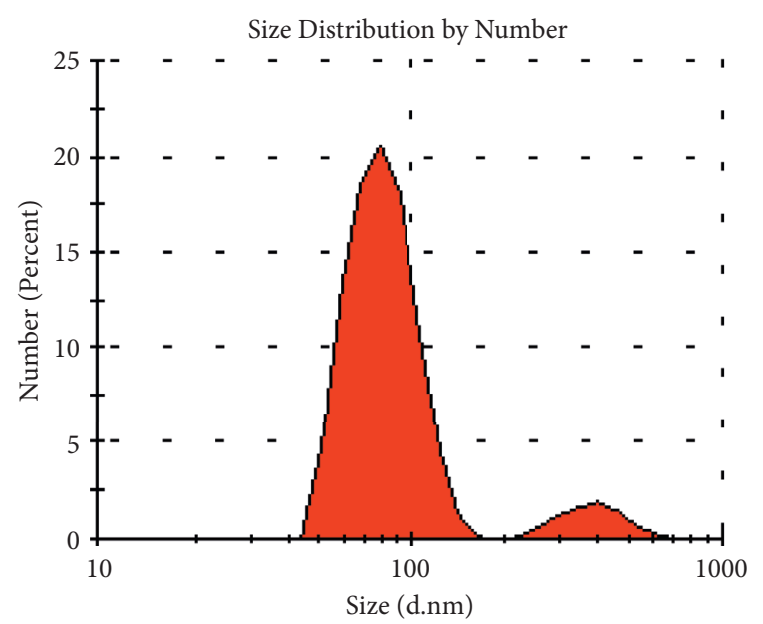

$\mathrm{ZnO}$ before magnetic stirring

(a)

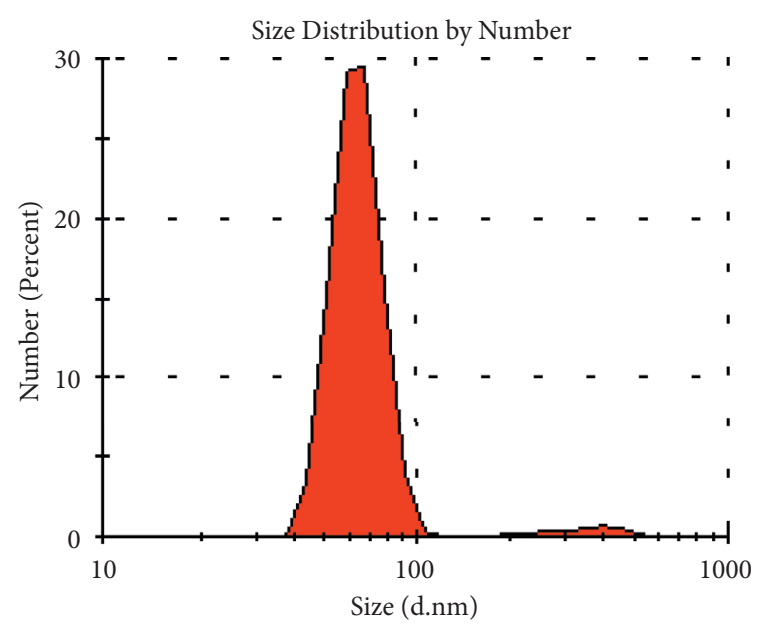

$\mathrm{ZnO}$ after magnetic stirring

(b)

FIgURE 2: Zetasizer analysis results (a) before magnetic stirring and (b) after magnetic stirring.

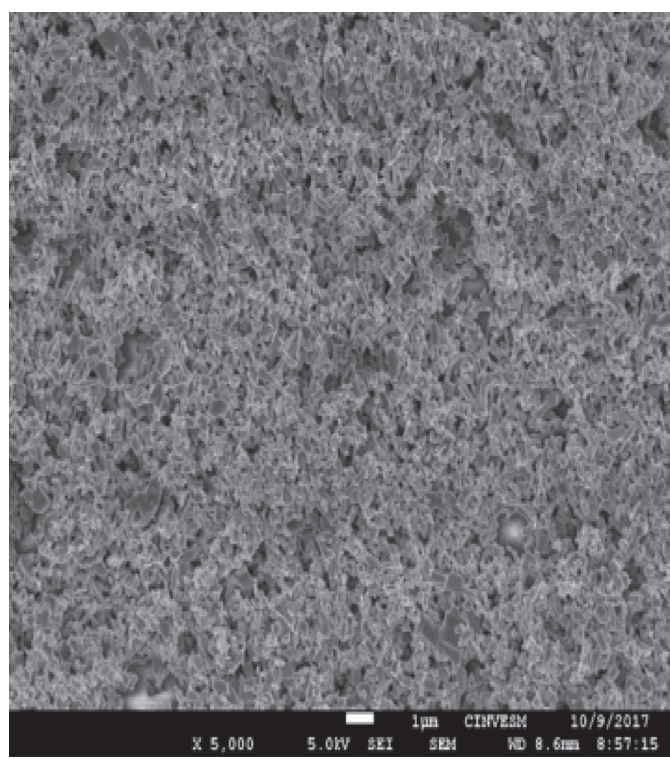

(a)

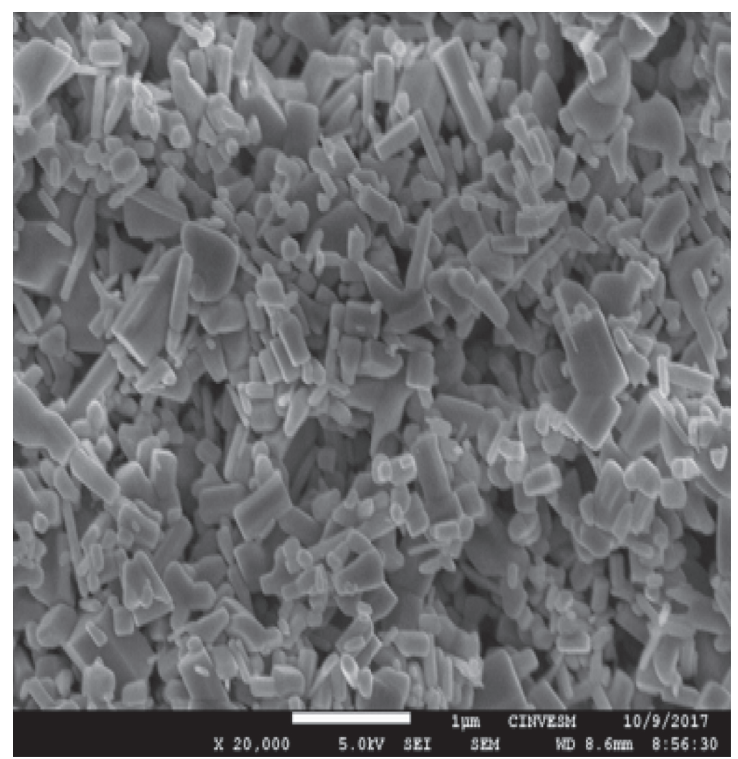

(b)

FIgURE 3: SEM images of $\mathrm{ZnO}$ film, showing the morphology at different magnifications: (a) $\times 5,000$ and (b) $\times 20,000$.

arrangement of nano and submicronic particles. There are variations in the shape, diameter, and crystal size of the particles. The smaller particles represent the NPs in suspension within the colloid as per the Zetasizer analysis, while the larger particles represent the submicronic particles from the precipitate. Particles have different orientations, which indicate the existence of different crystalline planes of the material.

To identify the size range of the precipitate particles, we measured the larger $\mathrm{ZnO}$ particles using a high-quality image with a magnification of $\times 50000$, as shown in Figure 4. The particles size varied from less than $100 \mathrm{~nm}$ to just over $400 \mathrm{~nm}$.
3.3. EDS. The EDS analysis identified the characteristic peaks of oxygen and zinc, as shown in Figure 5. No other elements were identified, which indicates the purity of the deposited $\mathrm{ZnO}$. According to the EDS report, the weight percentages and atomic percentages of $\mathrm{Zn}$ and $\mathrm{O}$ in the film are 76.81; 23.19 and 55.22; 44.78, respectively, which is close to the bulk $\mathrm{ZnO}$ weight percentage ( 80 for $\mathrm{Zn}$ and 20 for O) [16]. The EDS analysis did not identify any of the other small peaks shown in Figure 5. They either represent negligible traces of other elements from the paste or noise from the amplifiers and microphonics of the equipment (a typical problem associated with EDS measurements). 


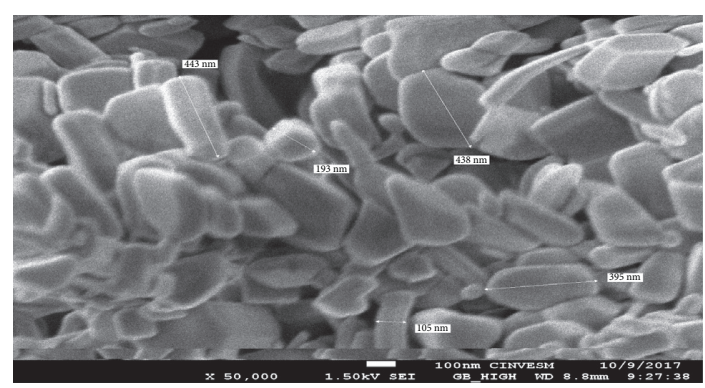

Figure 4: Arbitrary size measurement of the larger $\mathrm{ZnO}$ particles.

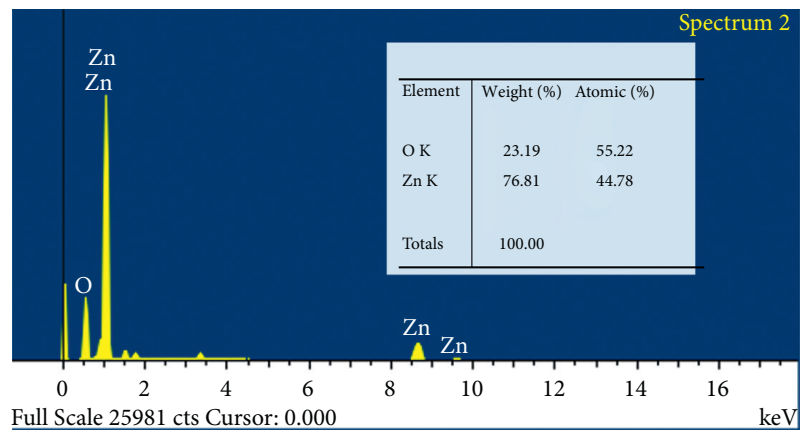

FIGURE 5: EDS analysis for the reported $\mathrm{ZnO}$ film.

3.4. XRD. Figure 6(a) shows the XRD analysis result of the $\mathrm{ZnO}$ thin film. The XRD pattern of the thin film shows polycrystalline phases with the following $h, k, l$ Miller indices: (100), (002), (101), (102), (110), (103), (200), (112), and (201). This result coincides with the standard $\mathrm{ZnO}$ pattern in the hexagonal wurtzite phase (crystallographic chart JCPDS \#36-1451). There is no evidence of remnant materials or impurities as no distant peaks were detected. The sharp diffraction peaks indicate good crystallinity of the NPs in the film. The peaks are slightly shifted to the left in comparison to the standard $\mathrm{ZnO}$ peaks, as shown in Figure 6(b) and quantified in Table 1 . This shift could be a result of the annealing temperature used to deposit the $\mathrm{ZnO}$ film $[17,18]$, which is considered as an expansion deformation in the crystal lattice of the $\mathrm{ZnO}$ particles.

The average crystallite size $(D)$ was estimated using the Scherrer formula [19]:

$$
D=\frac{K \lambda}{\beta_{h k l} \cos \theta},
$$

where $\lambda, \beta$, and $\theta$ are the $\mathrm{X}$-ray wavelength, the full width at half maximum (FWHM) height of the diffraction peak, and Braggs diffraction angle, respectively. The average crystallite size calculated from the diffraction peaks was $43.25 \mathrm{~nm}$. The induced strain $\varepsilon$ due to imperfection and distortion of the crystal in each plane was calculated using the following formula [20]:

$$
\varepsilon=\frac{\beta_{h k l}}{4 \tan \theta}
$$

The average strain value calculated from the diffraction peaks was $1.954 \times 10^{-3}$. The detailed results are presented in Table 1.
For the hexagonal structure of $\mathrm{ZnO}$, the space between the different planes is related to the lattice parameters of the crystal structure $a$ and $c$ and the Miller indices $h, k$, and $l$ by the following relationship [19]:

$$
\frac{1}{d_{(h k l)}^{2}}=\frac{4}{3}\left(\frac{h^{2}+h k+k^{2}}{a^{2}}\right)+\frac{l^{2}}{c^{2}} .
$$

Given that $d=n \lambda / 2 \sin \theta$ and with $n=1$ (first-order approximation),

$$
\sin ^{2} \theta=\frac{\lambda^{2}}{4 a^{2}}\left[\frac{4}{3}\left(h^{2}+k^{2}+h k\right)+\left(\frac{a}{c}\right)^{2} l^{2}\right] .
$$

The parameter $a$ for the plane (100) is calculated by the following:

$$
a=\frac{\lambda}{\sqrt{3} \sin \theta} .
$$

The parameter $c$ for the plane (002) is calculated by the following:

$$
c=\frac{\lambda}{\sin \theta} .
$$

The volume $V$ of the crystal is calculated by the following:

$$
V=\left(\frac{\sqrt{3}}{2}\right)\left(a^{2}\right)(c) .
$$

The lattice parameter values of the deposited $\mathrm{ZnO}$ thin film are slightly higher than those of the standard $\mathrm{ZnO}$, as shown in Table 2. This indicates a small expansive deformation in the crystal lattice of the $\mathrm{ZnO}$ and confirms what was indicated by the small shift in the XRD diffraction peaks (Figure 6(b)). This small expansive deformation results in an increase in $0.728 \%$ in the volume of the $\mathrm{ZnO}$ crystal.

The dislocation density $(\delta)$, which represents the number of defects in the sample, is defined as the length of the dislocation lines per unit volume of the crystal and is calculated using the following equation [21]:

$$
\delta=\frac{1}{D^{2}}
$$

where $D$ is the average crystalline size. The calculated dislocation density $(\delta)$ is $5.35 \times 10^{-4} \mathrm{~nm}^{-2}$.

The $\mathrm{Zn}-\mathrm{O}$ bond length is calculated by the following formula [22]:

$$
L=\sqrt{\left(\frac{a^{2}}{3}+\left(\frac{1}{2}-u\right)^{2} c^{2}\right)}
$$

where $a$ and $c$ are the crystalline parameters and $u$ is the positional parameter in the wurtzite structure, a measure of the amount in which each atom moves with respect to the next one along the $c$ axis. The parameter $u$ is determined by the following equation: 


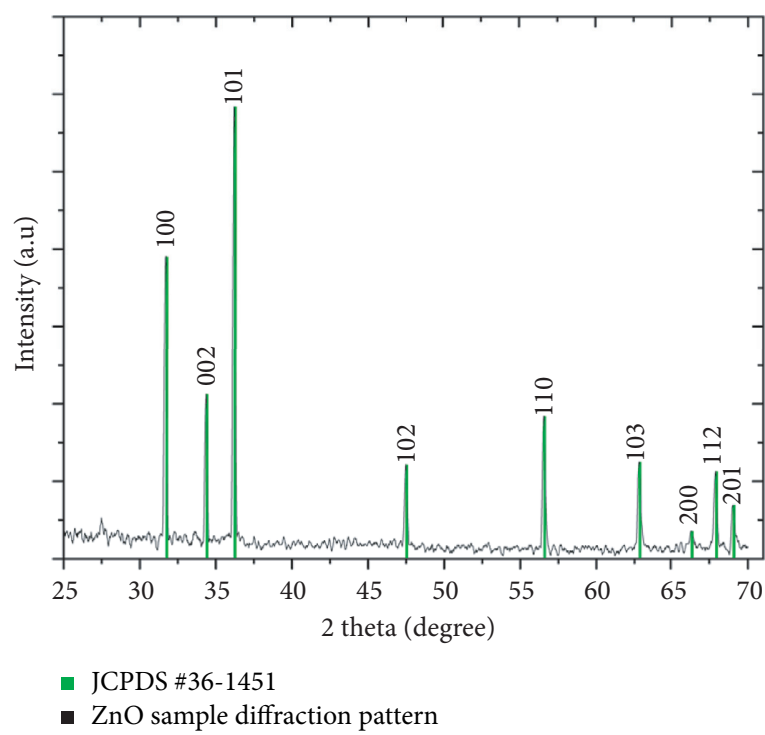

(a)

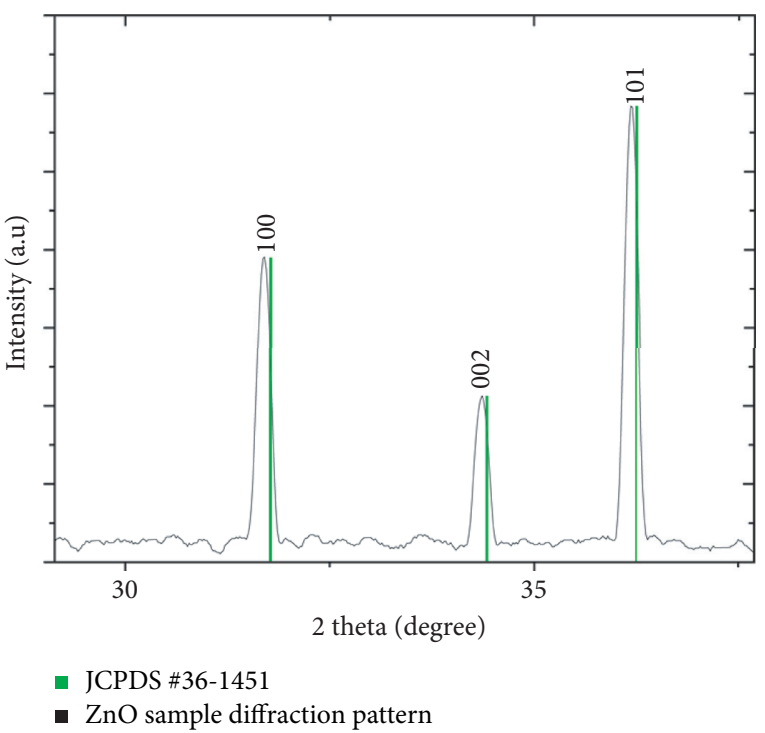

(b)

FIgure 6: (a) The XRD pattern of the $\mathrm{ZnO}$ film (the green lines indicate the XRD peaks of the standard wurtzite $\mathrm{ZnO}$ ). (b) Zoom in on the 3 peaks with the highest intensity where a small shift to the left is observed.

TABLE 1: Calculations of the crystal size $D$ and the induced stress $\varepsilon$ for each one of the peaks of the XRD pattern of the $\mathrm{ZnO}$ film.

\begin{tabular}{lcccccc}
\hline $\begin{array}{l}(h k l) \\
\text { plane }\end{array}$ & $\begin{array}{c}2 \theta^{\circ} \\
\text { standard }\end{array}$ & $2 \theta^{\circ}$ & $\beta^{\circ}$ & $D(\AA)$ & $d(\mathrm{~nm})$ & $\mathcal{E}$ \\
\hline 101 & 36.253 & 36.1886 & 0.1824 & 458.17 & 2.480 & 0.00243 \\
100 & 31.770 & 31.69293 & 0.18283 & 451.65 & 2.820 & 0.00281 \\
002 & 34.422 & 34.35762 & 0.18429 & 451.17 & 2.607 & 0.00260 \\
110 & 56.603 & 56.54802 & 0.21181 & 425.84 & 1.626 & 0.00171 \\
103 & 62.864 & 62.81478 & 0.2205 & 422.10 & 1.478 & 0.00157 \\
102 & 47.539 & 47.4834 & 0.20776 & 417.70 & 1.913 & 0.00206 \\
112 & 67.963 & 67.90056 & 0.21575 & 443.86 & 1.379 & 0.00139 \\
102 & 69.100 & 69.04072 & 0.22919 & 420.67 & 1.359 & 0.00145 \\
200 & 66.380 & 66.34685 & 0.23628 & 401.66 & 1.407 & 0.00157 \\
\hline
\end{tabular}

TABLe 2: Values of $a, c$, and $V$ for the grown $\mathrm{ZnO}$ particles compared with standard $\mathrm{ZnO}$ values.

\begin{tabular}{lcccc}
\hline & $a(\AA)$ & $c(\AA)$ & $\begin{array}{c}\text { Volume } \\
\left(\AA^{3}\right)\end{array}$ & $\begin{array}{c}\text { Volume difference } \\
(\%)\end{array}$ \\
\hline $\begin{array}{l}\text { Standard } \\
\text { ZnO }\end{array}$ & 3.249 & 5.206 & 47.621 & 0 \\
ZnO film & 3.258 & 5.217 & 47.968 & 0.728 \\
\hline
\end{tabular}

$$
u=\frac{a^{2}}{3 c^{2}}+0.25 .
$$

The calculated bond length of $\mathrm{Zn}-\mathrm{O}$ is $2.695 \AA$.

3.5. Optical Properties. Figure 7 shows the optical absorbance spectrum of the $\mathrm{ZnO}$ film. The band gap energy estimated from the absorption spectrum is $\sim 3.80 \mathrm{eV}$ which is higher than the standard value of $\mathrm{ZnO}(3.37 \mathrm{eV})$.

Given the particle size range detected in the Zetasizer analysis $(35-100 \mathrm{~nm})$ and the average crystalline size calculated for the deposited $\mathrm{ZnO}$ film $(43.25 \mathrm{~nm})$, the higher optical

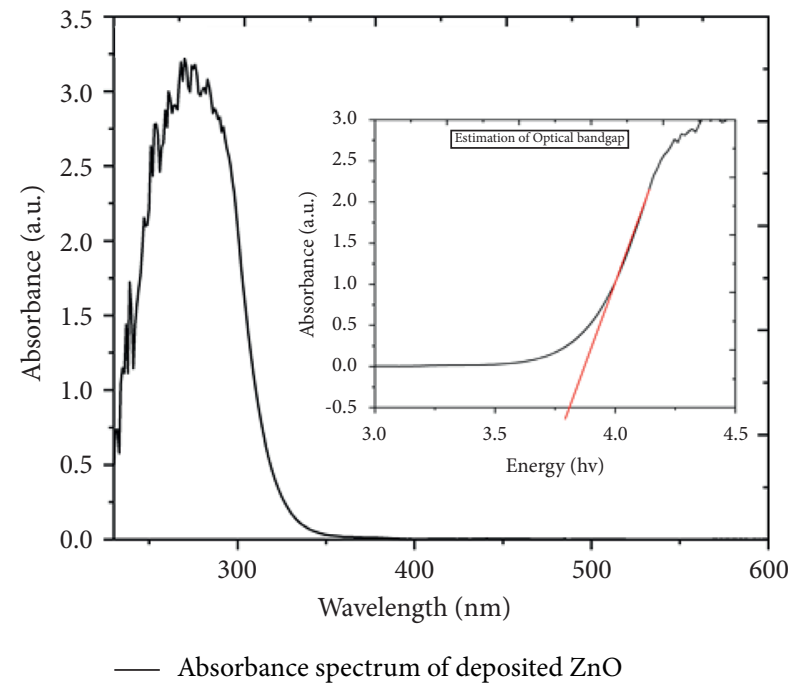

Figure 7: Optical absorbance spectrum and optical bandgap estimation of the $\mathrm{ZnO}$ film. The insert shows the estimation of the optical band gap.

bandgap value could be due to quantum confinement, which modifies the bandgap value of semiconductor materials. In general, the structural and optical properties of the sample coincide with what other studies reported for $\mathrm{ZnO}$ synthesized by sol-gel and deposited by spin-coating [23-25]. In this work, we recovered $\mathrm{ZnO}$ NPs from a commercial product through a process that implies simplicity and low cost.

\section{Conclusions}

We chemically extracted the $\mathrm{ZnO}$ particles from a commercial product (Dr. Bell's Pomade) and deposited them on glass substrates by spin-coating. The $\mathrm{ZnO}$ thin film is 
mesoporous, with uniformly arranged nanostructured particles of different shapes. The film is formed by pure hexagonal wurtzite $\mathrm{ZnO}$, with no impurities or remnants of other materials. The average crystalline size of the $\mathrm{ZnO}$ particles is $\sim 43.25 \mathrm{~nm}$. The particles showed a slight volume expansion of $0.728 \%$ due to a tensile strain of $1.954 \times 10^{-3}$. All calculated structural parameters are similar to those of the standard $\mathrm{ZnO}$ values. The estimated bandgap from the transmittance spectrum is larger than the standard bandgap of $\mathrm{ZnO}$. A quantum confinement effect could explain the larger bandgap. Our work opens the door to the recycling of nanoparticles, an area that has little research to date but great importance and potential for the future [26]. The reported $\mathrm{ZnO}$ film has suitable properties for optoelectronic and photovoltaic applications. One of the possible applications is as an ETL in third-generation solar cells.

\section{Data Availability}

The data used to support the findings of the study are available from the corresponding author upon request.

\section{Conflicts of Interest}

The authors declare that there are no conflicts of interest regarding the publication of this paper.

\section{Acknowledgments}

The authors are grateful to CONACYT \& SENER (Secretariat of Energy) of Mexico for the financial support to carry out this work under Project No. 254667 Consolidation of LENERSE (Laboratory of Energy Renewable of SudEst). The authors wish to thank Dr. Patricia Quintana for the help provided by their experimental characterization laboratories of National Council for Science and Technology of Mexico \& Mixed Fund, Yucatan State Government with contract 2008108160 and National Council for Science and Technology of Mexico under Project Nos. 2009-01-123913, 29-(2692, 4643), 188345, and 204822. The authors I. V. Perez-Quintana, M. Acosta, and J. A. Mendez-Gamboa would like to thank National Council for Science and Technology of Mexico \& Secretariat of Energy (Mexico) under Project No. 254667 Consolidation of LENERSE (Laboratory of Energy Renewable of SudEst).

\section{References}

[1] G. Wisz, I. Virt, P. Sagan, P Potera, and R Yavorskyi, "Structural, optical and electrical properties of zinc oxide layers produced by pulsed laser deposition method," Nanoscale Research Letters, vol. 12, no. 253, pp. 253-256, 2017.

[2] B. Joshi, P. Saxena, and N. Khera, "Optical Properties of Zinc Oxide ( $\mathrm{ZnO})$ Films for Applications in Optical Devices: MATLAB Simulation," in Proceedings of 3rd International Conference On Computing For Sustainable Global Development, pp. 2261-2265, INDIACom, New Delhi, India, March 2016.

[3] A. Kathalingam, S. Valanarasu, V. Senthilkumar, and J.-K. Rhee, "Piezo and photoelectric coupled nanogenerator using $\mathrm{CdSe}$ quantum dots incorporated $\mathrm{ZnO}$ nanowires in
ITO/ZnO NW/Si structure," Materials Chemistry and Physics, vol. 138, no. 1, pp. 262-269, 2013.

[4] A. Kathalingam and J.-K. Rhee, "Fabrication and characterization of solution processed $\mathrm{n}-\mathrm{ZnO}$ nanowire/p-Si heterojunction device," Journal of Nanoscience and Nanotechnology, vol. 12, no. 9, pp. 6948-6954, 2012.

[5] M. S. White, D. C. Olson, S. E. Shaheen, N. Kopidakis, and D. S. Ginley, "Inverted bulk-heterojunction organic photovoltaic device using a solution-derived $\mathrm{ZnO}$ underlayer," Applied Physics Letters, vol. 89, no. 14, pp. 1-3, Article ID 143517, 2006.

[6] M. Y. Chang, C. C. Lin, and C. K. Huang, "Sol-gel process $\mathrm{ZnO}$ thin film as the electron transport layer in inverted polymer solar cell," in Proceedings of AM-FPD 2016 - 23rd International Workshop on Active-Matrix Flatpanel Displays and Devices: TFT Technologies and FPD Materials, pp. 239242, Avanti Kyoto Hall, Kyoto, Japan, July 2016.

[7] M. B. Tahir, H. Javad, K. Nadeem, and A. Majid, "ZnO THIN FILMS: recent development, future perspectives and applications for dye sensitized solar cell," Surface Review and Letters, vol. 25, no. 7, Article ID 1930001, 2018.

[8] M. A. Mahmud, N. K. Elumalai, M. B. Upama et al., "Low temperature processed $\mathrm{ZnO}$ thin film as electron transport layer for efficient perovskite solar cells," Solar Energy Materials and Solar Cells, vol. 159, pp. 251-264, 2017.

[9] M. R. Awual and M. M. Hasan, "A ligand based innovative composite material for selective lead(II) capturing from wastewater," Journal of Molecular Liquids, vol. 294, Article ID 111679, 2019.

[10] M. Awual, T. Yaita, T. Kobayashi, H. Shiwaku, and S. Suzuki, "Improving cesium removal to clean-up the contaminated water using modified conjugate material," Journal Of Environmental Chemical Engineering, vol. 8, no. 2, Article ID 103684, 2019.

[11] F. Lekoui, S. Hassani, M. Ouchabane et al., "Elaboration and characterization of $\mathrm{Mg}$-doped $\mathrm{ZnO}$ thin films by thermal evaporation: annealing temperature effect," Brazilian Journal of Physics, vol. 51, no. 3, pp. 544-552, 2021.

[12] A. Salah, A. Saad, and A. Aboud, "Effect of Co-doping level on physical properties of $\mathrm{ZnO}$ thin films," Optical Materials, vol. 113, Article ID 110812, 2021.

[13] L. G. Daza, I. V. Perez-Quintana, B. Cruz-Muñoz, M. HerreraSalvador, and R. Castro-Rodríguez, "Twisted-motion substrate with sustained azimuthal rotation effect on the growth of AZO thin films by rf-sputtering," Optik, vol. 234, Article ID 166561, 2021.

[14] E. A. Martín-Tovar, R. Castro-Rodríguez, L. G. Daza et al., "Structural and optical properties of $\mathrm{ZnO}$ thin films prepared by laser ablation using target of $\mathrm{ZnO}$ powder mixture with glue," Bulletin of Materials Science, vol. 40, no. 3, pp. 467-471, 2017.

[15] Mursal, Irhamni, Bukhari, and Z. Jalil, "Structural and optical properties of zinc oxide $(\mathrm{ZnO})$ based thin films deposited by sol-gel spin coating method," Journal of Physics: Conference Series, vol. 1116, Article ID 032020, 2018.

[16] M. S. Geetha, H. Nagabhushana, and H. N. Shivananjaiah, "Green mediated synthesis and characterization of $\mathrm{ZnO}$ nanoparticles using Euphorbia Jatropa latex as reducing agent," Journal of Science: Advanced Materials And Devices, vol. 1, no. 3, pp. 301-310, 2016.

[17] A. Goktas, A. Tumbul, Z. Aba, and M. Durgun, "Mg doping levels and annealing temperature induced structural, optical and electrical properties of highly c-axis oriented $\mathrm{ZnO}: \mathrm{Mg}$ 
thin films and $\mathrm{Al} / \mathrm{ZnO}: \mathrm{Mg} / \mathrm{p}-\mathrm{Si} / \mathrm{Al}$ heterojunction diode," Thin Solid Films, vol. 680, pp. 20-30, 2019.

[18] S. Kurtaran, "Al doped $\mathrm{ZnO}$ thin films obtained by spray pyrolysis technique: influence of different annealing time," Optical Materials, vol. 114, Article ID 110908, 2021.

[19] B. Cullity, Elements of X-Ray Diffraction, Addison-Wesley Publishing Company, Inc., Phillipines, Asia, 1978.

[20] A. R. Stokes and A. J. C. Wilson, "The diffraction of X rays by distorted crystal aggregates - I," Proceedings of the Physical Society, vol. 56, no. 3, pp. 174-181, 1944.

[21] G. K. Williamson and R. E. Smallman, "III. Dislocation densities in some annealed and cold-worked metals from measurements on the X-ray debye-scherrer spectrum," Philosophical Magazine, vol. 1, no. 1, pp. 34-46, 1956.

[22] H. Morkoç and U. Ozgür, Zinc Oxide: Fundamentals, Materials and Devices Technology, Wiley-VCH Verlag GmbH \& Co. KGaA, Weinheim, Germany, 2009.

[23] R. Amari, B. Deghfel, A. Mahroug, A. A. Mohamad, A. Boukhari, and N. Selmi, "Effects of Mn doping on the structural, morphological, electronic and optical properties of $\mathrm{ZnO}$ thin films by sol-gel spin coating method: an experimental and DFT+U study," Physica B: Condensed Matter, vol. 577, Article ID 411766, 2020.

[24] T. S. Anilkumar, M. L. Girija, and J. Venkatesh, "Synthesis and characterization of $\mathrm{ZnO}$ thin films," AIP Conference Proceedings, vol. 1728, Article ID 020509, 2016.

[25] J. Zhang, X. Sun, T. Qi, G. Ren, Y. Shan, and Q. Dong, "Characterization of ZnO films prepared by sol-gel method," AIP Conference Proceedings, vol. 1820, Article ID 020002, 2017.

[26] R. M. Kamel, A. Shahat, W. H. Hegazy, E. M. Khodier, and M. R. Awual, "Efficient toxic nitrite monitoring and removal from aqueous media with ligand based conjugate materials," Journal of Molecular Liquids, vol. 285, pp. 20-26, 2019. 